\title{
Visual optical biosensors based on DNA-functionalized polyacrylamide hydrogels
}

\author{
Imran Khimji ${ }^{1}$, Erin Y. Kelly ${ }^{1}$, Youssef Helwa, Michael Hoang and Juewen Liu* \\ Department of Chemistry and Waterloo Institute for Nanotechnology, University of Waterloo, \\ Waterloo, Ontario, N2L 3G1 \\ 1. These two authors contributed equally to this work. \\ Email: liujw@uwaterloo.ca
}

\begin{abstract}
Biosensors are devices that can provide quantitative or semi-quantitative analytical information about target molecules, where molecular recognition is based on biomolecular interactions. In recent years, DNA has emerged as a useful molecule for biosensors development since DNA can not only recognize its complementary strand, but also metal ions, small molecules, proteins and cells utilizing DNA aptamer technology. Converting DNA binding events into useful biosensors often require sensor immobilization. Among the various materials for sensor immobilization, hydrogels are particularly attractive. Hydrogels are crosslinked hydrophilic polymer networks that undergo swelling in water. In a gel, DNA immobilization can take place in 3D, allowing for high DNA loading capacity. Hydrogels are transparent, offering low optical background. The gel volume is affected by many environmental parameters such as temperature, $\mathrm{pH}$, ionic strength, and solvent composition. In this paper, we present a concise summary of recent developments in DNA-functionalized hydrogel biosensors for visual detection. Detailed methods for immobilizing DNA biosensors in monolithic polyacrylamide gels and gel microparticles are supplied.
\end{abstract}

Keywords: DNA; hydrogels; aptamers; biosensors; fluorescence 


\section{Introduction}

\subsection{Immobilized biosensors.}

Biosensors are analytical devices that can measure the concentration of target analytes based on a biological recognition reaction. In recent years, the market for biosensors has grown significantly, mainly driven by the medical and environmental applications. A biosensor contains at least two components, one for target binding and the other for signal transduction. For most practical applications, a third component is needed to immobilize biosensors for device incorporation and ease of handling. While many surfaces and materials have been developed for biosensor immobilization, including gold [1,2], carbon-based materials (e.g. graphite, graphene, and carbon nanotubes) [3-5], and silica or glass [6], we will focus our discussion on hydrogels. Hydrogels are crosslinked hydrophilic polymer networks that swell in water [7-15]. Compared to many other types of materials, immobilization in hydrogels occurs in 3-D, allowing a high loading capacity of sensing molecules. At the same time, hydrogels have good optical transparency convenient for visual detection. Since hydrogels are prepared in solution, they can be readily made into different forms including monoliths, thin films, and micro/nanoparticles, each showing different cargo loading capacity and releasing properties [16]. For example, gel micro/nanoparticles are useful for drug delivery while gel films are ideal for making smart surface coatings, and monolithic gels are easy to handle, observe, and to incorporate into devices.

\subsection{Stimuli responsive hydrogels.}

Hydrogels swell significantly in water. The amount of retained water or swelling is influenced by environmental conditions, such as temperature, $\mathrm{pH}$, salt, light and electric field [17]. Therefore, smart hydrogels have been designed to sense these stimuli based on gel volume change. A commonly cited example is the poly $\mathrm{N}$-isopropylacrylamide (pNIPAm) hydrogel that shows temperaturedependent volume change $[18,19]$. At low temperature, the water-polymer interaction is strong and the gel is highly swelled. Beyond a lower critical solution temperature (LCST), the hydrogen bonds 
between the polymer and water start to break and the gel collapses to interact with itself through the hydrophobic interactions [20]. In addition to the gel volume change, if the crosslink is disrupted, a gelto-sol transition is produced. Finally, various optical responses might be introduced into the gel, where the gel is used as a matrix for immobilization. These stimuli responsive gels are highly attractive for various applications including controlled drug release, sensing, switchable cell culture substrates and for flow control [21-26].

\subsection{Chemically responsive hydrogels.}

For many bio-related applications, it is desirable to have hydrogels that can detect metal ions, small molecule metabolites, nucleic acids, and proteins. An example is insulin release from hydrogels in response to glucose concentration change for treating diabetes. Towards this goal, biomolecular interactions need to be introduced inside the hydrogels [27-30]. Many previous works have employed peptides, protein enzymes and antibodies for molecular recognition. For example, Miyata and coworkers respectively attached IgG and its antigen to polymer chains. These functionalized polymers formed a hydrogel crosslinked by antibody-antigen interactions [27], which swelled in the presence of free antigens since it can reduce the crosslinking density.

\subsection{DNA for molecular recognition.}

In the past three decades, various new technologies have enabled the application of DNA as a platform for molecular recognition [31-37]. For example, DNA oligonucleotides and even whole genes can be routinely synthesized and various chemical modifications can be added at designated positions. With polymerase chain reaction (PCR), many methods have been developed to select DNA aptamers that can bind to essentially any molecule of choice [38-40]. DNA has many advantages compared to proteins for designing stimuli responsive hydrogels. DNA has higher stability compared to proteins. While DNA can also be heat denatured, it can be re-natured at lower temperature. In contrast, protein denaturation is usually irreversible. Many aptamers can rival antibodies in binding affinity and specificity (especially for small molecule targets), but aptamers have less batch-to-batch variations. 
Finally, since the structure of DNA is highly predictable, many rational design strategies can be employed to for biosensor development.

\subsection{DNA attachment.}

Hydrogels can be made up of pure DNA [41,42]. From the analytical chemistry standpoint however, such gels are very expensive and unlikely to have good sensitivity. Sensing gels are more often prepared by attaching DNA to synthetic polymer backbones. In this paper, we only describe DNA covalently attached to the gel matrix, while DNA entrapment will not be discussed. Two methods are often used to attach DNA. First, amino-modified DNA reacts with a monomer or a polymer containing a reactive succinimidyl ester to form an amide bond (Figure 1A). This reaction takes place either before or after gel formation, allowing DNA distribution within the gel or only to the gel surface, respectively. In the second method, acrydite-modified DNA is directly incorporated via co-polymerization during gel formation (Figure 1B). An acrydite DNA has a similar reactivity as free acrylamide monomers, allowing a high incorporation efficiency [43]. While the field of DNA-functionalized hydrogels began in 1996 [44], most of the developments have occurred in the past ten years [45-48]. In this article, we only provide a concise review of recent developments in visual detection using DNA-functionalized hydrogels. Detailed protocols for preparing monolithic gels and gel microparticles are also supplied. 


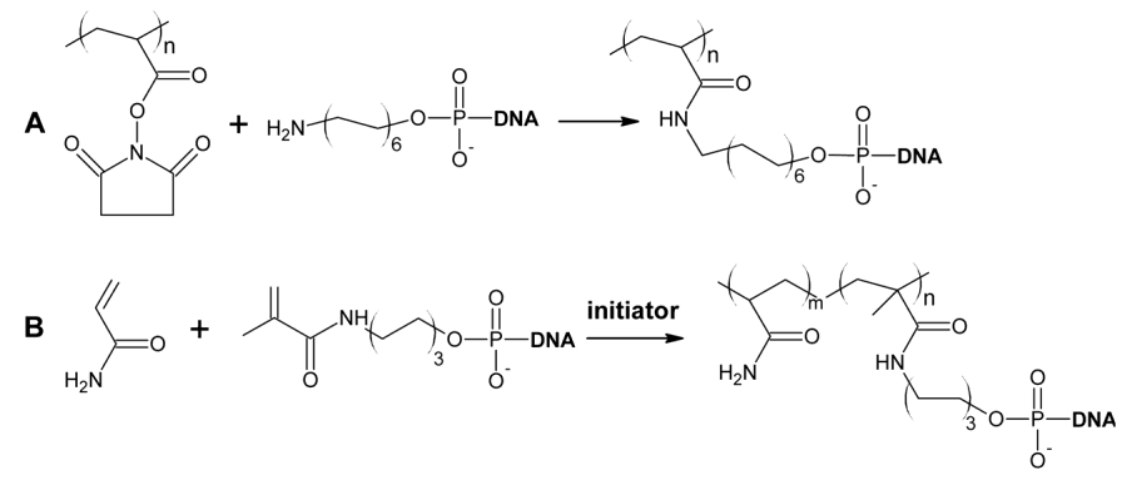

Figure 1. The two types of conjugate chemistry for covalently attaching DNA to hydrogel. (A) Aminomodified DNA reacts with a polymer containing a succinimidyl ester on the backbone. (B) Copolymerization of acrydite-modified DNA into polyacrylamide. Reproduced from Ref. 46 with permission from The Royal Society of Chemistry.

\section{DNA-functionalized hydrogels as biosensors.}

\subsection{Sensing based on gel-sol transition.}

By crosslinking a hydrogel using reversible DNA hybridization, it is easy to design sensors based on gel-to-sol transition. One of the first systems reported by Nagahara and Matsuda involved two different polymers, each with a different DNA sequence attached [44]. Gel is formed with a linker DNA and can be disrupted upon heating (Figure 2A). Although this system could in principle detect the linker DNA, it is unlikely to be practically useful since a very high concentration of linker DNA is required to form a gel. For example, to achieve $1 \%$ of crosslinking density it usually requires $\sim 1 \mathrm{mM}$ linker DNA. The linker DNA can also be removed by adding a complementary target DNA to induce gel dissolution. However, the dissolution kinetics is often quite slow since it takes a long time for the target DNA to diffuse into the gel [49-51]. 


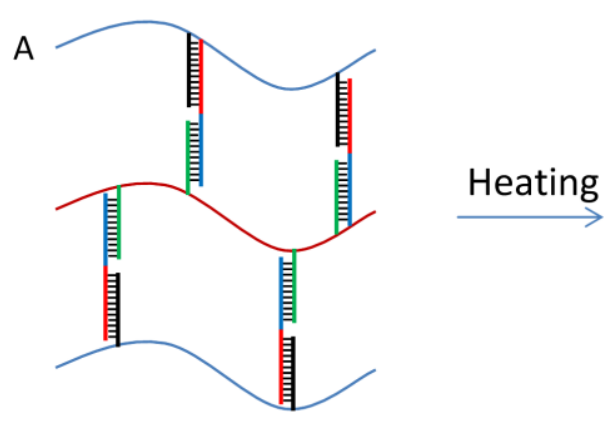

Gel

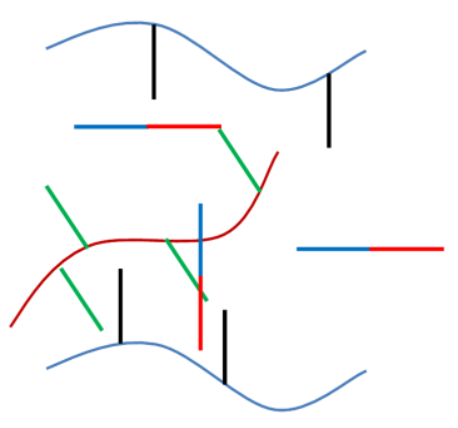

Sol

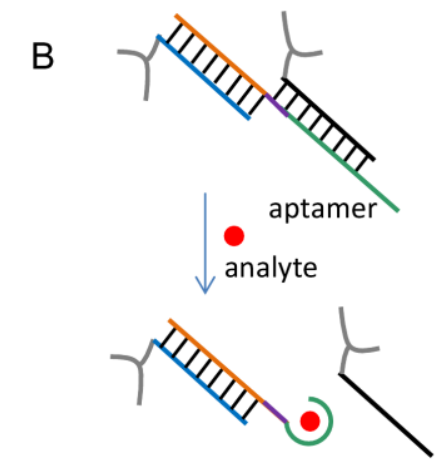

TGAGTAGACACTTCTCTTGGACCC

ACTCATCTGTGAAGAGAACCTGGGGGATATTGCGGAAGGT

Figure 2. Schemes of gel transition to the sol state upon destabilization of linker DNA by heating (A) or by adding the target analyte of the aptamer embedded in the linker DNA (B). The adenosine aptamer sequence and gel linkages in (B) are also shown.

Fast responding gels were prepared when an aptamer was used as crosslinker by Tan and coworkers (Figure 2B) [52]. Without adenosine, the aptamer acted as a stable crosslinker to hold the gel together. Addition of adenosine induced aptamer folding to break the crosslink. Since adenosine is a small molecule, its diffusion into the monolithic gel was much faster. For example, $2 \mathrm{mM}$ adenosine completely dissolved the gel within 15 min. By crosslinking the gel using a pH-sensitive DNA I-motif, the gel can be disrupted within a minute by adding base [53]. Dual response was also possible by crosslinking the gel with two types of aptamers and effective gel dissolution was achieved only when both target molecules were present [54].

To facilitate visualization of the gel-to-sol transition, red gold nanoparticles (AuNPs) are often entrapped in the gel [52,53]. In addition, Yang, Tan and co-workers entrapped amylase within a cocaine aptamer crosslinked hydrogel [55]. In the presence of cocaine, amylase was released due to hydrogel dissolution to convert amylose into glucose, resulting in a colorless solution in the presence iodine. Otherwise an intense blue color was observed due to the amylose/iodine interaction. Since 
amylase is highly active, the gel does not have to completely dissolve to show a strong color effect; even $2 \mu \mathrm{M}$ cocaine can be visually detected.

Using the same systems, Yan et al. fabricated a gel with entrapped glucoamylase using aptamers as crosslinker [56]. Glucoamylase is also an enzyme that can break down amylose. Upon addition of target molecules, the gel breaks down and releases the enzyme to produce glucose, allowing for a quantitative readout using a personal glucose meter (PGM). Detection limits of 1.6, 4.4 and 7.7 $\mu \mathrm{M}$ cocaine were achieved in buffer, urine and blood samples, respectively. Another feature of this system is the high stability; refrigerated hydrogels were still viable after 3 months of storage.

A switchable sol-gel transition was created by Willner and co-workers in the presence of $\mathrm{K}^{+}$ [57]. When free $\mathrm{K}^{+}$was introduced, G-rich DNA attached to polymer chains formed G-quadruplex to crosslink the gel. Addition of 18 -crown-6-ether removes $\mathrm{K}^{+}$from the gel, reverting the system back to the sol state. As low as $0.1 \mathrm{mM} \mathrm{K}^{+}$was enough to induce gel formation in $100 \mathrm{~s}$, after which $75 \mu \mathrm{M}$ of the crown ether was sufficient to revert the gel back to the sol state.

In addition to using aptamers, the Yang group recently used DNAzymes as a crosslinker to create a gel [58]. This DNAzyme cleaves its DNA substrate in the presence of $\mathrm{Cu}^{2+}[59,60]$. AuNPs were pre-trapped within the gel, resulting in a reddish colour. Upon the addition of $\mathrm{Cu}^{2+}$, catalytic cleavage was induced, allowing the AuNPs to fully disperse in the buffer. This results in a visible color change. $\mathrm{Cu}^{2+}$ concentrations as low as $10 \mu \mathrm{M}$ could be detected in $1.5 \mathrm{hr}$. This system also represented high selectivity, showing negligible AuNP release when $1 \mathrm{mM}$ of other metal ions were added.

\subsection{Sensors based on gel volume change.}

The gel-to-sol transition is easy to visualize. At the same time, controlled release for sensing and for biomedical applications has also been realized [61-63]. One disadvantage is that the gels cannot be easily regenerated after dissolution. To address this, a number of smart gels with volume change have been reported. Murakami and Maeda employed DNA strands with each of the ends labeled with an amino group to permanently crosslink the gel (but not through hybridization) [64]. The DNA can 
fold into a hairpin (Figure 3A), resulting in compact gels due to the short DNA end-to-end distance. The addition of the cDNA resulted in the formation of a rigid ds-DNA and gel expansion. If the linker DNA did not have any initial secondary structure, gel shrinkage upon hybridization to the cDNA was observed [65]. The change of the gel volume is quite small (only 20\%) [66,67]. To increase the sensitivity of detection, interferometry and gel photonic crystals have been reported [68,69]. Another way to control gel swelling is shown in Figure 3B, where the gel is mainly crosslinked by conventional bis-acrylamide. Hybridization of DNA establishes more crosslinking points and thus shrinks the gel [66]. In a detailed study, Gao et al tuned gel swelling kinetics by changing the length of cDNA that would compete with the linker DNA [66]. At the same time, increasing the crosslink density decreases the swelling rate, whereas destabilization of the linker at a temperature close to the DNA melting point increases the swelling rate.

Wang and Li reported detection of avian influenza virus using quartz crystal microbalance (QCM) sensor [70]. A gel was formed by linking the influenza aptamer with a cDNA and was immobilized onto a QCM. If the H5N1 virus was introduced, it would compete with the cDNA to bind with the aptamer, swelling the gel and causing a signal on QCM. In just 30 minutes, a detection limit of 0.0128 HA unit could be achieved. Another approach was used by the Zhong and Tan groups to produce a hydrogel that contracted in the presence of visible light, but swelled under UV [71,72]. This was achieved by using an azobenzene modified DNA. Under visible light, crosslinking occurs via hybridization of the complementary strands, causing the gel to contract. Exposure to UV disrupts the DNA hybridization, allowing the gel to swell. 

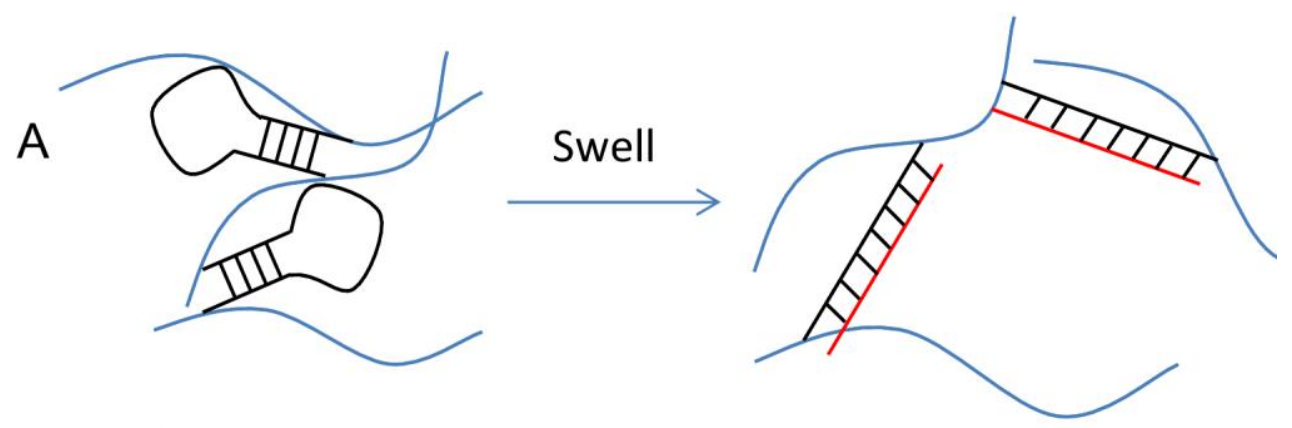

\section{B}

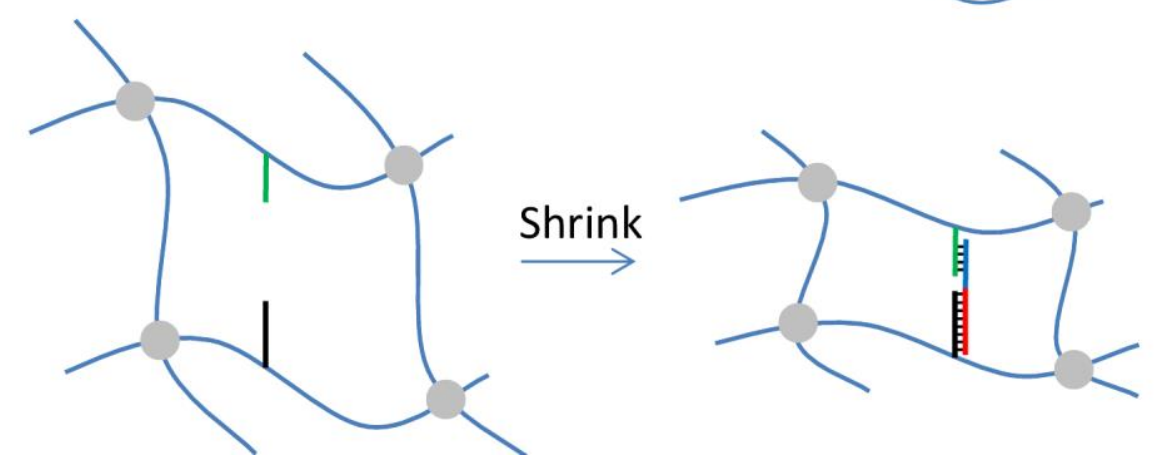

Figure 3. Hydrogel volume change by DNA hybridization. (A) The hairpin opens up after adding the cDNA, causing the gel to expand and the volume to increase. (B) The gel shrinks when the cDNA is added.

\subsection{Immobilization of optical sensors}

In most of the previous examples, the DNA components in gel bare some level of mechanical roles to support the gel-sol transition or volume expansion. One drawback of using DNA as a crosslink to observe gel mechanical property is the high concentration of DNA required. For example, a $4 \%$ hydrogel has a monomer concentration of $\sim 560 \mathrm{mM}$ acrylamide. Therefore, even $0.2 \%$ crosslinking would require $1 \mathrm{mM}$ of DNA. For bioanalytical chemists using DNA as a probe, the normal concentrations are in $\mathrm{nM}$ or low $\mu \mathrm{M}$. Using high concentration of DNA not only increases the cost but also reduces sensitivity. To solve this problem, we use the gel matrix only for sensor immobilization and the DNA is used to generate optical signal. 
To demonstrate the concept, we immobilized $\mathrm{Hg}^{2+}$ binding DNA in the gel (Figure 4A). These DNA strands are rich in thymine (Figure 4B) [73]. In the presence of $\mathrm{Hg}^{2+}$, the aptamer adopts a hairpin configuration that produces strong green fluorescence with SYBR Green I [74]. Furthermore, through careful tuning of the gel charge, the detection limit was improved. ${ }^{12}$ It needs to be noted that the gel can enrich $\mathrm{Hg}^{2+}$ since the DNA has high affinity for mercury, allowing visual detection of just $10 \mathrm{nM} \mathrm{Hg}^{2+}$ (Figure 4C). The immobilized sensor also allows for regeneration, protection of DNA from nucleases and drying for long-term storage. A similar system was adapted to detect lead using a guanine-rich DNA, allowing visual detection of $20 \mathrm{nM} \mathrm{Pb}^{2+}$ [75]. In addition to using DNA staining dyes, DNA-functionalized AuNPs were also used to stain the gels for visual DNA and ATP detection [76-79].
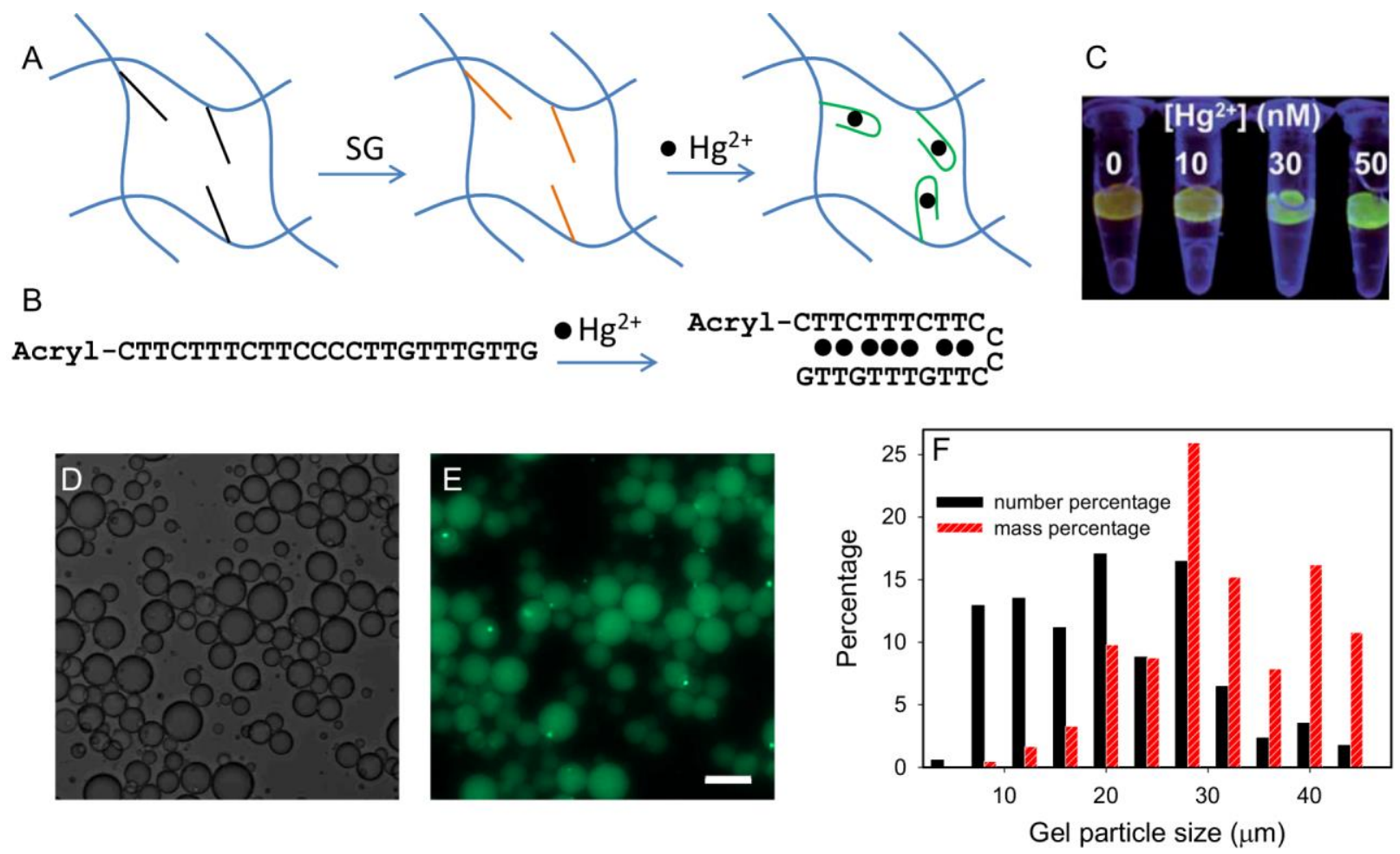

Figure 4. $\mathrm{Hg}^{2+}$-binding DNA functionalized hydrogel for $\mathrm{Hg}^{2+}$ DNA. (A) A weak orange fluorescence is observed following addition of SG. Addition of $\mathrm{Hg}^{2+}$ causes a hairpin to form, resulting in strong green fluorescence. (B) The DNA sequence used and resulting hairpin configuration in $\mathrm{Hg}^{2+}$. (C) A 
photograph showing fluorescence change after addition of various concentrations of $\mathrm{Hg}^{2+}$. Hydrogel microparticle characterization using optical microscopy under transmission light (D) and fluorescence mode (E). Scale bar $=40 \mu \mathrm{m}$. (F) Size distribution of the gel beads. Reprinted with permission from Ref 73 and 84. Copyright 2010, 2012 American Chemical Society.

Recently it was discovered that fluorescent gold and silver nanoclusters (AgNCs) can also be used to detect $\mathrm{Hg}^{2+}$ [80]. The DNA sequence in Figure 5A can bind $\mathrm{Ag}^{+}$and form two types of $\mathrm{AgNCs}$ emitting red and green fluorescence, respectively. Some of the red emitter can be converted to the green one upon exposure to $\mathrm{Hg}^{2+}[81,82]$. We attributed this conversion to the oxidation of the red emitter to the green oxidized form. After immobilizing the DNA in hydrogel, its ability to form AgNC was maintained (Figure 5B). Addition of $\mathrm{Hg}^{2+}$ still resulted in the green fluorescence in the gel (Figure 5C). In this case, DNA is used only as the template for producing and stabilizing the fluorescent AgNCs. It is the intrinsic property of the $\mathrm{AgNC}$ to be responsible for the selective detection of $\mathrm{Hg}^{2+}$. Willner and co-workers also prepared DNA-based hydrogels that can produce yellow and red emitting AgNCs [83].

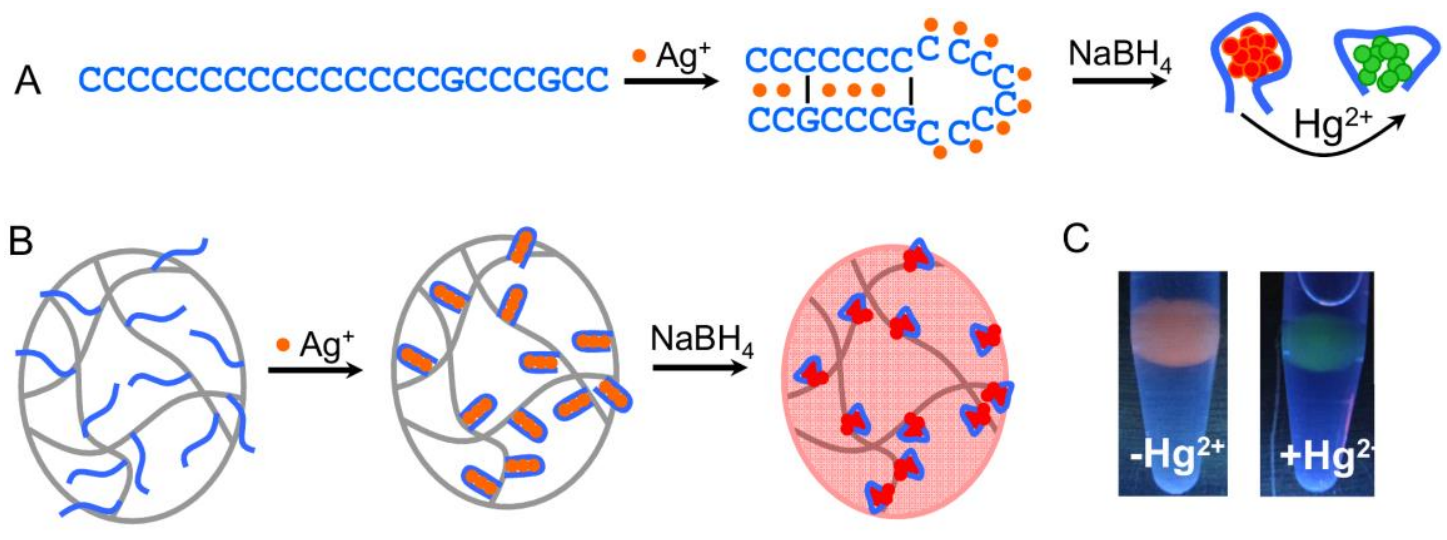


Figure 5. (A) DNA templated AgNC synthesis producing both red and green emitters. Adding $\mathrm{Hg}^{2+}$ can further induce the conversion from red to green and the quenching of red emitter. (B) Schematics of immobilizing AgNCs in hydrogels. (C) Photograph of immobilized sensor in the presence or absence of $\mathrm{Hg}^{2+}$. Reprinted with permission from Ref 81. Copyright 2013 Elsevier.

In most of the examples reviewed above, monolithic gels were prepared, and the reaction kinetics were quite slow due to the long diffusion distances. Typically, $1 \mathrm{hr}$ or longer is required for detection. The signaling kinetics can be improved by preparing hydrogel microparticles $[84,85]$. Using the same DNA in Figure 4B, hydrogel microparticles for $\mathrm{Hg}^{2+}$ detection were prepared with an inverse emulsion polymerization method. The gel beads were spherical (Figure 4D), with most being in the size range from 10 to $50 \mu \mathrm{m}$ (Figure $4 \mathrm{~F}$, black bars). By calculating the mass percentage, the average size was around $30 \mu \mathrm{m}$ (red bars). After staining the DNA using SYBR Green I, a fluorescence signal was obtained using blue light excitation (Figure 4E), and the fluorescent particles co-localized with the image obtained using the transmission mode, suggesting the DNA was inside the gel. Quantitative kinetic measurements confirmed that the kinetics for signal change took place in a few minutes for such gel beads.

\section{Experimental methods}

In this section, we describe the detailed methods for preparing DNA-functionalized monolithic hydrogels and hydrogel microparticles. In particular, conditions for polymerizing hydrogel microparticles are more stringent.

\subsection{Materials.}

The DNA sample was purchased from Integrated DNA Technologies (Coralville, IA). The sequence of the $\mathrm{Hg}^{2+}$ binding DNA is (acrydite-5'-CTTCTTTCTTCCCCTTGTTTGTTG). The same method can be used to immobilize other DNA sequences. For such short oligonucleotides, standard 
desalting purification is sufficient. The chemicals for gel preparation are quite standard in molecular biology work, which are the same for carrying out polyacrylamide gel electrophoresis. $40 \%$ acrylamide:bis-acrylamide $=29: 1$ gel solution, $N, N^{\prime}$-methylenebisacrylamide, acrylamide powder, Span 80, ammonium persulphate (APS), and $\mathrm{N}, \mathrm{N}, \mathrm{N}^{\prime}, \mathrm{N}^{\prime}$-tetramethylethylenediamine (TEMED) were purchased from VWR. Mercury perchloride and other metal salts were obtained from Sigma-Aldrich. Sodium nitrate and tris(hydroxymethyl)aminomethane (Tris) were purchased from Mandel Scientific (Guelph, Ontario, Canada). 10,000× SYBR Green I in dimethyl sulfoxide (DMSO) was from Life Technologies.

\subsection{Synthesis of DNA-functionalized monolithic hydrogels.}

Preparation of polyacrylamide gel is a routine practice in many laboratories. The typical gel volume ranges from $\sim 5$ to over $30 \mathrm{~mL}$. For DNA immobilization, however, even our monolithic gels are just below $0.1 \mathrm{~mL}$, requiring slightly different formulation and procedures. The commercial gel stocks typically contains $40 \%$ acrylamide:bis-acrylamide (19:1 or $29: 1)$. It is important to protect them from light exposure. For long-term storage they can be placed in a $4{ }^{\circ} \mathrm{C}$ refrigerator. We typically use a round-bottom 96-well plate to mold the gels. Other types of containers can also be used, such as those with flat bottoms or with different shapes. In a typical reaction, the following chemicals are mixed following this order: water $(204 \mu \mathrm{L})$, gel stock $(30 \mu \mathrm{L}, 40 \%)$, Tris nitrate buffer $(30 \mu \mathrm{L}, \mathrm{pH} 8.0,0.5$ M), $\mathrm{NaNO}_{3}(15 \mu \mathrm{L}, 2 \mathrm{M})$, and acrydite-modified DNA $(6 \mu \mathrm{L}, 0.5 \mathrm{mM})$. At this moment, the sample is ready to be initiated for polymerization. The initiator mixture is freshly prepared by weighing $20-50 \mathrm{mg}$ of APS powder in a weighing boat. Water is directly added to the boat to make $10 \%(\mathrm{w} / \mathrm{w})$ APS solution. To this APS solution, TEMED is added to make a final concentration of 5\% APS. To the above gel solution, $15 \mu \mathrm{L}$ of the initiator mixture is added and after a brief vortex, the samples are quickly transferred into a 96-well plate with each well containing $70 \mu \mathrm{L}$ solution. 
The above protocol is for preparing 4 gels and more gels can be prepared by increasing the volume of the reagents. However, if more than 10 gels are to be made, it is suggested to prepare them in two or more batches (e.g. add the initiator separately) to avoid gel formation before transferring the sample to the 96-well plate. In the formulation, note that the effect of buffer is to maintain a high $\mathrm{pH}$ since polymerization does not readily occur at low $\mathrm{pH}$. The Tris buffer can also be replaced by HEPES buffer. We found that adding salt is helpful for gel formation and $\mathrm{NaNO}_{3}$ can also be replaced by $\mathrm{NaCl}$ for most applications. To prepare $\mathrm{Hg}^{2+}$ sensitive gels, we refrained from using $\mathrm{NaCl}$ to minimize the potential interference from $\mathrm{Cl}^{-}$. Here the final gel concentration is $4 \%$, a good concentration for handling. At higher than $8 \%$, the gel becomes very brittle and easy to break. On the other hand, if below $3 \%$, the gel is very soft and cannot maintain a well-defined shape.

The gels are polymerized for $1 \mathrm{hr}$ at room temperature. Longer time incubation causes drying of the gels and should be avoided. To take the gels out of the wells, we typically add a few drops of water as a lubricant. The gels need to be thoroughly washed to remove all the impurities including free monomers, initiators, salts and free DNA. This can be achieved by soaking the gels in a large volume of water (typically $50 \mathrm{~mL}$ Milli-Q water for 10 gels). After soaking for 4-10 hrs, the water is discarded and fresh water is added. After soaking for three times, the gels are ready to be used.

\subsection{Hydrogel microparticles.}

Polyacrylamide hydrogel microparticles are prepared using the inverse emulsion polymerization method [84-86]. First, a gel stock is prepared by dissolving acrylamide (9 g) and $N, N^{\prime}-$ methylenebisacrylamide $(1 \mathrm{~g})$ in a total volume of $50 \mathrm{~mL}$. Note that it takes a long time to fully dissolve bisacrylamide since our concentration approached its solubility limit. Sonication helps for the dissolution process. In a typical reaction, $3 \mathrm{~mL}$ of the gel stock is added to a $20 \mathrm{~mL}$ scintillation vial and Tris buffer ( $\mathrm{pH} 8.3$, final $25 \mathrm{mM}$ ) is added. A final of $2 \mu \mathrm{M}$ acrydite-modified DNA is also added. The concentration of DNA can be adjusted to fit the need of sensor design. Then $3 \mathrm{~mL}$ cyclohexane is added as the oil phase and span $80(200 \mu \mathrm{L})$ is added to as the surfactant. At this moment, a clear 
separation of the bottom aqueous phase and the top oil phase should be observed and the yellow span 80 stays at the interface. A fresh sample of APS is prepared $(33 \% \mathrm{w} / \mathrm{w}$, e.g. dissolve $75 \mathrm{mg}$ APS in 150 $\mu \mathrm{L}$ water) and $24 \mu \mathrm{L}$ of it is added to the aqueous phase. The vial is then cooled on ice for 5 min and purged with nitrogen for 2 min to remove oxygen. After capping the vial, the inverse emulsion is formed under a stirring rate of $800 \mathrm{rpm}$ for $5 \mathrm{~min}$. At this moment, $24 \mu \mathrm{L}$ of TEMED is added to start the polymerization reaction, which is allowed to continue for $4 \mathrm{hr}$ under $800 \mathrm{rpm}$ stirring. Afterwards, the stirring is stopped and the emulsion phase separates to allow removal of the top cyclohexane layer. For every $100 \mu \mathrm{L}$ of the aqueous phase, $1 \mathrm{~mL}$ of ethanol is added to dissolve it. After $10 \mathrm{~min}$ of soaking in ethanol, the solution is centrifuged for $5 \mathrm{~min}$ at 15,000 rpm and the ethanol is removed. The gel beads are soaked in $1 \mathrm{~mL}$ of water for $5 \mathrm{~min}$ and washed by centrifugation. This washing process is repeated 4 times in water to remove unreacted monomers and initiators. Finally, the gels are dispersed at a concentration of $10 \mathrm{mg} / \mathrm{mL}$ (considering only the dry mass of the gel). Since it is more difficult to prepare hydrogel microparticles, the effect each variable is presented below.

\subsubsection{Effect of pH}

With $3 \mathrm{~mL}$ aqueous phase, it is expected to harvest $\sim 3 \mathrm{~g}$ gel beads if the polymerization reaction proceeded normally. Sometimes, the gel could swell more if more water is provided, giving more than 3 g gels. We used the gel weight to quantify the effect of various variables in this synthesis process. First, it is very important to carefully adjust the $\mathrm{pH}$. The yields are extremely low (e.g. $\sim 3 \%$ ) if only water was used $(\mathrm{pH} \sim 6)$. High yield is achieved when $25 \mathrm{mM}$ Tris buffer $(\mathrm{pH} 8.3)$ or HEPES (pH 7.6) is included in the aqueous phase (Figure 6A).

\subsubsection{Nitrogen purging}

Normally, when we prepare monolithic gel, no nitrogen purging step is carried out. However, the yield is much lower if the nitrogen purging step is omitted for making hydrogel microparticles (Figure 6B). The main effect herein is to remove oxygen which is a terminator for radical polymerization. 


\subsubsection{Gel Percentage}

In the above protocol, $\sim 20 \%$ gel is prepared and a similar yield can be obtained with a $10 \%$ gel. However, the gel yield is much lower at $6.7 \%$ or below (Figure $6 \mathrm{C}$ ). For a comparison, high quality monolithic gels can be formed even at $4 \%$.

\subsubsection{Effect of APS and TEMED}

Note that higher APS and TEMED concentrations produce a faster reaction and some temporary light orange color. High yield is achieved with greater than $24 \mu \mathrm{L}$ of both and the yield falls rapidly when the volume of the two is below $16 \mu \mathrm{L}$ (Figure 6D). Note that we keep the volume ratio of these two at 1:1 in our tests. It is also important to use freshly prepared initiators.

\subsubsection{Effect of span 80}

With $3 \mathrm{~mL}$ of the aqueous phase and $3 \mathrm{~mL}$ of cyclohexane, an almost complete reaction is achieved with 200 or $300 \mu \mathrm{L}$ span 80 , while the yield drops by half when $50 \mu \mathrm{L}$ span 80 is used (Figure $6 \mathrm{E})$.

\subsubsection{Reaction time}

The gel yield reaches a plateau at around $1 \mathrm{hr}$ after adding TEMED (Figure 6F). Charged hydrogels can also be synthesized by incorporating a fraction of charged monomers such as allylamine for cationic gels and 2-acrylamido-2-methyl-1-propansulfonic acid (AMPS) for anionic gels. It is important to ensure that the $\mathrm{pH}$ is still within the optimal range with the charged monomers. 

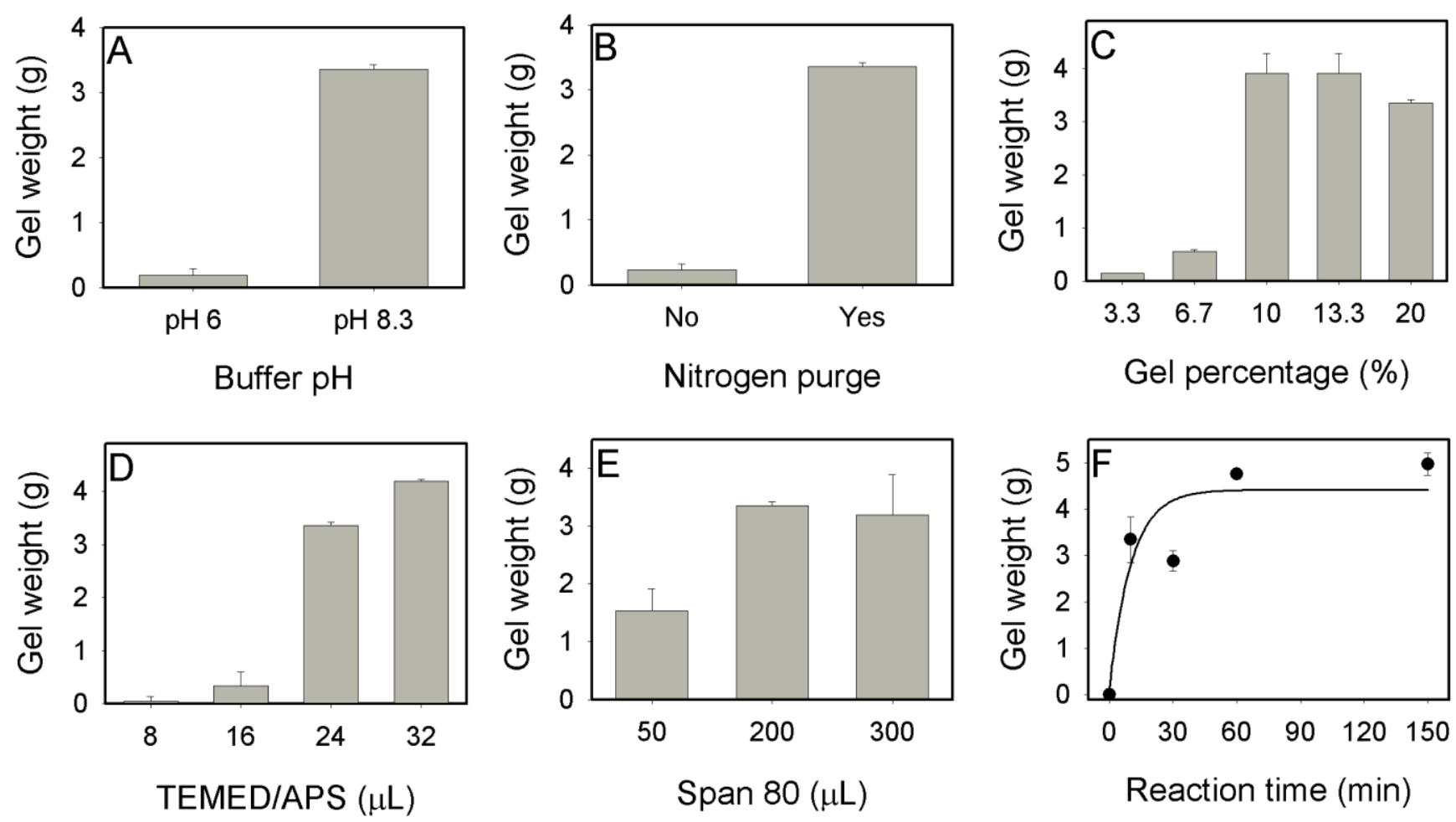

Figure 6. The obtained gel weight from $3 \mathrm{~mL}$ aqueous phase synthesis under various conditions. (A) pH. (B) Nitrogen purging the samples for 2 min. (A) Gel monomer concentration in the aqueous phase. (D) Volume of catalyst/initiator concentration. The APS solution is 50\%. (E) The volume of Span 80 added. (F) Gel yield as a function of reaction time after adding TEMED.

\section{4. $\mathrm{Hg}^{2+}$ Detection.}

In a typical experiment, each gel is soaked in $1 \mathrm{~mL}$ of buffer $\mathrm{A}(20 \mathrm{mM} \mathrm{NaNO}, 10 \mathrm{mM}$ HEPES, $\mathrm{pH}$ 7.6) containing $\mathrm{Hg}^{2+}$ or other metal ions. Larger volumes of the sample can also be used to

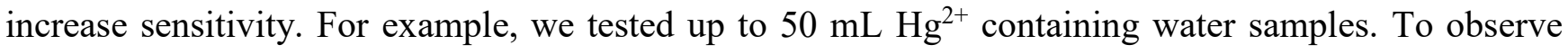
fluorescence, $2 \mu \mathrm{L}$ of $250 \times$ concentrated $(500 \mu \mathrm{M})$ SYBR Green I is then added. The mixtures are soaked for $1 \mathrm{hr}$ at room temperature on a shaker. A long time is required due to the slow diffusion kinetics and long diffusion distances in the monolithic gels. The gels are excited with a handheld UV lamp at $365 \mathrm{~nm}$ at a distance $\sim 10 \mathrm{~cm}$ from the gels. UV protection goggles are used for visual 
observation. The fluorescence can be recorded using a commercial digital camera (Canon PowerShot SD 1200 IS). For quantitative analysis, the gels are imaged with a gel documentation system (Alpha Innotech FluorChem FC2). The excitation wavelength is at $365 \mathrm{~nm}$ and the emission was collected using a green filter. The gel fluorescence can also be quantified using a fluorescence microplate reader by exciting at $480 \mathrm{~nm}$ and scanning the emission wavelength.

\section{Conclusions.}

In summary, we have provided a concise review of DNA-functionalized hydrogels as biosensors and focused on the recent developments in visual sensors. It is clear that hydrogels serve not only as a simple substrate for DNA immobilization, but it also provides numerous other possibilities through reagent entrapment, controlled release, analyte enrichment and DNA protection. These features are not readily available for most other types of substrates commonly used for biomolecular immobilization. We only reviewed polyacrylamide gels in this work but there are many other types of gel forming materials such as silica-based gels which are also very popular for interfacing with DNA sensors [87-89]. DNA itself is a polymer and it is actually possible to prepare hydrogels made of pure DNA. Therefore, interfacing DNA with synthetic polymers to make hydrogels is not too far of a stretch. We described detailed protocols to prepare monolithic hydrogels and hydrogel microparticles. We believe these will serve as a useful basis for further development of this field for advanced applications in biomedical diagnosis, controlled drug release, in vivo sensing and environmental monitoring.

\section{Acknowledgement}

Funding for the work from the Liu lab described in this article is from the University of Waterloo, the Discovery Grant from the Natural Sciences and Engineering Research Council of Canada (NSERC), Early Researcher Award from the Ontario Ministry of Research and Innovation and Canadian Foundation for Innovation. 


\section{References:}

[1] N.L. Rosi, C.A. Mirkin, Chem. Rev. 105 (2005) 1547-1562.

[2] T.M. Herne, M.J. Tarlov, J. Am. Chem. Soc. 119 (1997) 8916-8920.

[3] C.H. Lu, H.H. Yang, C.L. Zhu, X. Chen, G.N. Chen, Angew. Chem. Int. Ed. 48 (2009) 47854787.

[4] E.S. Jeng, A.E. Moll, A.C. Roy, J.B. Gastala, M.S. Strano, Nano Lett. 6 (2006) 371-375.

[5] J. Wang, Electroanalysis 17 (2005) 7-14.

[6] L.A. Chrisey, G.U. Lee, C.E. O'Ferrall, Nucleic Acids Res. 24 (1996) 3031-3039.

[7] R. Langer, D.A. Tirrell, Nature 428 (2004) 487-492.

[8] E.S. Gil, S.M. Hudson, Prog. Polym. Sci. 29 (2004) 1173-1222.

[9] Y. Qiu, K. Park, Adv. Drug Deliver. Rev. 53 (2001) 321-339.

[10] K.Y. Lee, D.J. Mooney, Chem. Rev. 101 (2001) 1869-1879.

[11] B. Jeong, S.W. Kim, Y.H. Bae, Adv. Drug Deliver. Rev. 54 (2002) 37-51.

[12] A.S. Hoffman, Adv. Drug Deliver. Rev. 54 (2002) 3-12.

[13] W.E. Hennink, C.F. van Nostrum, Adv. Drug Deliver. Rev. 54 (2002) 13-36.

[14] C. Tsitsilianis, Soft Matter 6 (2010) 2372-2388.

[15] S. Banta, I.R. Wheeldon, M. Blenner, Annu. Rev. Biomed. Eng. 12 (2010) 167-186.

[16] I. Tokarev, S. Minko, Soft Matter 5 (2009) 511-524.

[17] Y. Osada, H. Okuzaki, H. Hori, Nature 355 (1992) 242-244.

[18] S. Nayak, L.A. Lyon, Angew. Chem. Int. Ed. 44 (2005) 7686-7708.

[19] L. Hu, M.J. Serpe, Polymers 4 (2012) 134-149.

[20] X. Wang, X. Qiu, C. Wu, Macromolecules 31 (1998) 2972-2976.

[21] N.A. Peppas, J.Z. Hilt, A. Khademhosseini, R. Langer, Adv. Mater. 18 (2006) 1345-1360.

[22] N.A. Peppas, P. Bures, W. Leobandung, H. Ichikawa, Eur. J. Pharm. Biopharm. 50 (2000) $27-$ 46. 
[23] K. Gawel, D. Barriet, M. Sletmoen, B.T. Stokke, Sensors 10 (2010) 4381-4409.

[24] G.R. Hendrickson, M.H. Smith, A.B. South, L.A. Lyon, Adv. Funct. Mater. 20 (2010) 16971712.

[25] D.T. Eddington, D.J. Beebe, Adv. Drug Deliver. Rev. 56 (2004) 199-210.

[26] J. Hu, G. Zhang, S. Liu, Chem. Soc. Rev. 41 (2012) 5933-5949.

[27] T. Miyata, N. Asami, T. Uragami, Nature 399 (1999) 766-769.

[28] C. Wang, R.J. Stewart, J. Kopecek, Nature 397 (1999) 417-420.

[29] W.L. Murphy, W.S. Dillmore, J. Modica, M. Mrksich, Angew. Chem. Int. Ed. 46 (2007) 30663069.

[30] M. Ehrbar, R. Schoenmakers, E.H. Christen, M. Fussenegger, W. Weber, Nat. Mater. 7 (2008) 800-804.

[31] N.C. Seeman, Nature 421 (2003) 427-431.

[32] C. Lin, Y. Liu, H. Yan, Biochemistry 48 (2009) 1663-1674.

[33] F.A. Aldaye, A.L. Palmer, H.F. Sleiman, Science 321 (2008) 1795-1799.

[34] A.P. Alivisatos, K.P. Johnsson, X. Peng, T.E. Wilson, C.J. Loweth, M.P. Bruchez, Jr, P.G. Schultz, Nature 382 (1996) 609-611.

[35] C.A. Mirkin, R.L. Letsinger, R.C. Mucic, J.J. Storhoff, Nature 382 (1996) 607-609.

[36] J.J. Storhoff, C.A. Mirkin, Chem. Rev. 99 (1999) 1849-1862.

[37] J. Liu, Z. Cao, Y. Lu, Chem. Rev. 109 (2009) 1948-1998.

[38] C. Tuerk, L. Gold, Science 249 (1990) 505-510.

[39] A.D. Ellington, J.W. Szostak, Nature 346 (1990) 818-822.

[40] D.L. Robertson, G.F. Joyce, Nature 344 (1990) 467-468.

[41] S.H. Um, J.B. Lee, N. Park, S.Y. Kwon, C.C. Umbach, D. Luo, Nat. Mater. 5 (2006) 797-801.

[42] Y. Xing, E. Cheng, Y. Yang, P. Chen, T. Zhang, Y. Sun, Z. Yang, D. Liu, Adv. Mater. 23 (2011) 1117-1121. 
[43] F.N. Rehman, M. Audeh, E.S. Abrams, P.W. Hammond, M. Kenney, T.C. Boles, Nucleic Acids Res. 27 (1999) 649-655.

[44] S. Nagahara, T. Matsuda, Polymer Gels and Networks 4 (1996) 111-127.

[45] L. Peng, C.S. Wu, M. You, D. Han, Y. Chen, T. Fu, M. Ye, W. Tan, Chemical Science 4 (2013) 1928-1938.

[46] J. Liu, Soft Matter 7 (2011) 6757-6767.

[47] J. Liu, H. Liu, H. Kang, M. Donovan, Z. Zhu, W. Tan, Anal. Bioanal. Chem. 402 (2012) 187194.

[48] X. Xiong, C. Wu, C. Zhou, G. Zhu, Z. Chen, W. Tan, Macromol. Rapid. Comm. 34 (2013) DOI: 10.1002/marc.201300411.

[49] D.C. Lin, B. Yurke, N.A. Langrana, J. Biomech. Eng. 126 (2004) 104-110.

[50] B. Yurke, D.C. Lin, N.A. Langrana (2006) in "DNA Computing" (A. Carbone, and N. A. Pierce, Eds.), Vol. 3892, pp. 417-426.

[51] T. Liedl, H. Dietz, B. Yurke, F. Simmel, Small 3 (2007) 1688-1693.

[52] H.H. Yang, H.P. Liu, H.Z. Kang, W.H. Tan, J. Am. Chem. Soc. 130 (2008) 6320-6321.

[53] E.J. Cheng, Y.Z. Xing, P. Chen, Y. Yang, Y.W. Sun, D.J. Zhou, L.J. Xu, Q.H. Fan, D.S. Liu, Angew. Chem. Int. Ed. 48 (2009) 7660-7663.

[54] B.-C. Yin, B.-C. Ye, H. Wang, Z. Zhu, W. Tan, Chem. Comm. 48 (2012) 1248-1250.

[55] Z. Zhu, C.C. Wu, H.P. Liu, Y. Zou, X.L. Zhang, H.Z. Kang, C.J. Yang, W.H. Tan, Angew. Chem. Int. Ed. 49 (2010) 1052-1056.

[56] L. Yan, Z. Zhu, Y. Zou, Y. Huang, D. Liu, S. Jia, D. Xu, M. Wu, Y. Zhou, S. Zhou, C.J. Yang, J. Am. Chem. Soc. 135 (2013) 3748-3751.

[57] C.-H. Lu, X.-J. Qi, R. Orbach, H.-H. Yang, I. Mironi-Harpaz, D. Seliktar, I. Willner, Nano Lett. 13 (2013) 1298-1302. 
[58] H. Lin, Y. Zou, Y. Huang, J. Chen, W.Y. Zhang, Z. Zhuang, G. Jenkins, C.J. Yang, Chem. Comm. 47 (2011) 9312-9314.

[59] N. Carmi, H.R. Balkhi, R.R. Breaker, Proc. Natl. Acad. Sci. U.S.A. 95 (1998) 2233-2237.

[60] J. Liu, Y. Lu, J. Am. Chem. Soc. 129 (2007) 9838-9839.

[61] B. Soontornworajit, J. Zhou, M.T. Shaw, T.H. Fan, Y. Wang, Chem. Comm. 46 (2010) 18571859.

[62] Z.Y. Zhang, N.C. Chen, S.H. Li, M.R. Battig, Y. Wang, J. Am. Chem. Soc. 134 (2012) 1571615719.

[63] N.C. Chen, Z.Y. Zhang, B. Soontornworajit, J. Zhou, Y. Wang, Biomaterials 33 (2012) 13531362.

[64] Y. Murakami, M. Maeda, Biomacromolecules 6 (2005) 2927-2929.

[65] Y. Murakami, M. Maeda, Macromolecules 38 (2005) 1535-1537.

[66] M. Gao, K. Gawel, B.T. Stokke, Soft Matter 7 (2011) 1741-1746.

[67] D.C. Lin, B. Yurke, N.A. Langrana, J. Mater. Res. 20 (2005) 1456-1464.

[68] S. Tierney, B.T. Stokke, Biomacromolecules 10 (2009) 1619-1626.

[69] Y.J. Zhao, X.W. Zhao, B.C. Tang, W.Y. Xu, J. Li, L. Hu, Z.Z. Gu, Adv. Funct. Mater. 20 (2010) 976-982.

[70] R. Wang, Y. Li, Biosens. Bioelectron. 42 (2013) 148-155.

[71] L. Peng, M. You, Q. Yuan, C. Wu, D. Han, Y. Chen, Z. Zhong, J. Xue, W. Tan, J. Am. Chem. Soc. 134 (2012) 12302-12307.

[72] H. Asanuma, X. Liang, H. Nishioka, D. Matsunaga, M. Liu, M. Komiyama, Nat. Protocols 2 (2007) 203-212.

[73] N. Dave, P.-J.J. Huang, M.Y. Chan, B.D. Smith, J. Liu, J. Am. Chem. Soc. 132 (2010) 1266812673.

[74] J. Wang, B. Liu, Chem. Comm. (2008) 4759-4761. 
[75] Z.E. Jacobi, L. Li, J. Liu, Analyst 137 (2012) 704-709.

[76] A. Baeissa, N. Dave, B.D. Smith, J. Liu, ACS Appl. Mater. Inter. 2 (2010) 3594-3600.

[77] F. El-Hamed, N. Dave, J. Liu, Nanotechnology 22 (2011) 494011.

[78] A. Baeissa, N. Moghimi, J. Liu, RSC Advances 2 (2012) 2981-2987.

[79] H. Wang, Z. Chen, X. Fu, Y. Li, X. Tang, H. Wu, B. Zou, G. Zhou, Journal of Nanoscience and Nanotechnology 12 (2012) 6887-6892.

[80] J. Xie, Y. Zheng, J.Y. Ying, Chem. Comm. 46 (2010) 961-963.

[81] J.L. MacLean, K. Morishita, J. Liu, Biosens. Bioelectron. 48 (2013) 82-86.

[82] K. Morishita, J.L. MacLean, B. Liu, H. Jiang, J. Liu, Nanoscale 5 (2013) 2840-2849.

[83] W. Guo, R. Orbach, I. Mironi-Harpaz, D. Seliktar, I. Willner, Small 9 (2013) DOI: 10.1002/smll.201300055.

[84] Y. Helwa, N. Dave, R. Froidevaux, A. Samadi, J. Liu, ACS Appl. Mater. Inter. 4 (2012) 22282233.

[85] Y. Helwa, N. Dave, J. Liu, Soft Matter 9 (2013) 6151-6158.

[86] X.D. Liu, Y. Murayama, M. Matsunaga, M. Nomizu, N. Nishi, Int. J. Biol. Macromol. 35 (2005) 193-199.

[87] C. Carrasquilla, P.S. Lau, Y. Li, J.D. Brennan, J. Am. Chem. Soc. 134 (2012) 10998-11005.

[88] N. Rupcich, R. Nutiu, Y. Li, J.D. Brennan, Angew. Chem., Int. Ed. 45 (2006) 3295-3299.

[89] N. Rupcich, R. Nutiu, Y. Li, J.D. Brennan, Anal. Chem. 77 (2005) 4300-4307. 